\title{
El programa de ajuste estructural: una herencia difícil
}

\author{
Fco. Javier Ibisate
}

Todo comenzó con la euforia propia del triunfo del partido y del modelo-ARENA. Después de la euforia vino el encuentro con la dura realidad: la herencia difícil de una economia desarticulada. El lema de cambiar para mejorar les habia llevado al poder, pero bien pronto se comienza a sentir que este lema plantea un serio problema al gobierno. No todos los que votaron a favor del partido o en contra del contrario entendian de la misma manera este slogan. El sector privado, el más típico componente del partido-ARENA, entendió y apoyó el "cambiar" en el sentido de privatizar; menos Estado y más del sector privado. EI resto de los votos, y también los que no votaron, entendian y apoyaban el "mejorar" en el sentido de que por fin se iban a satisfacer las fundamentales necesidades humanas de las mayorias. Los unos iban a exigir cambiar, es decir privatizar; los otros iban a exigir mejorar, es decir socializar el bienestar. Es la dicotomia que en nuestro país presenta una economia social de mercado. Este es el reto que se ha echado encima el nuevo gobierno y que le puede ir enfrentando paulatinamente con quienes $b$ eligieron para cambiar y con quienes $b$ eligieron para mejorar. $Y$ el evangelio dice que es difícil servir a dos senores...

Con ello la herencia dificil se vuelve más difícil. Al recibir su mandato los miembros del nuevo gabinete desfilaron, uno por uno, ante la Asamblea Legislativa, exponiendo la situación de penuria en que reciblan sus respectivos ministerios. Un ano más tarde vemos aparecer en las pantallas de la televisión a algunos de estos ministros solicitando bondadosa y persuasivamente el apoyo mancomunado, el esfuerzo 
común de todos los grupos sociales al proyecto gubernamental. Pese a las promesas y proyecciones oficiales de que la prosperidad nos aguarda a la vuelta de la esquina tenemos la sensación de que la herencia sigue siendo difícil tanto por to recibido como por lo posteriormente realizado. Es lógico que los partidos de oposición hagan oposición, con frecuencia más revanchista que constructiva. Pero en buena parte ello se debe a que el propio partido oficial, como partido, como ejecutivo y como legislativo se ha convertido en coautor de la oposición a su posición. Cierta prepotencia y agresividad le resta capacidad de convocatoria para lograr el apoyo y esfuerzo común.

Aparte de las discusiones y discrepancias sobre la idoneidad y factibilidad social del programa de ajuste estructural en un entorno de economia de mercado, hay otro elemento que obstaculiza la adhesión al gobierno-ARENA: su limitado y distorsionado análisis de la historia y de la realidad nacional. Para ganar unas elecciones se pueden develar las deficiencias técnicas de la anterior administración pública, incluida la rentable corrupción; pero no se pueden ni deben identificar estas actividades coyunturales con las causas y reguladores estructurales de nuestra historia económica y social. Con ello el gobierno se está echando arena en los ojos, si las mismas causales del pasado están entorpeciendo sus proyecciones económicas del presente. Tampoco es muestra de gran pedagogia social o signo de un sincero espíritu de diálogo el reservar, en forma exclusiva y machacona, el calificativo de terroristas para los grupos alzados en armas, como si éste fuera el objetivo único de los insurgentes, y como si antes y fuera de estos grupos nunca en nuestro país hubiera existido el terrorismo. No es esta la mejor publicidad para captar la benevolencia más popular.

Por anadidura, el gobierno y los proyectistas del modelo oficial comienzan a admitir, en su primer ano de gestión, la presencia de factores intemos y extemos - "uuera de control"- que tuercen y obstaculizan sus proyecciones económicas y sociales. La indulgencia y comprensión que invocan para sí mismos nunca la demostraron en sus juicios contra sus opositores presentes y pasados. Con ello, el partido y el ejecutivo se están labrando una herencia aún más difícil.

\section{La herencla dificll}

"Cuando el gobierno empezó sus funciones hace diez meses, en junio de 1989, encontró un país atravensado una profunda crisis económica y social. El país estaba en guerra y la pobreza afectaba a más de la mitad de la población. Los desequilibrios económicos interno y externo eran agudos; el sistema bancario estaba virtualmente quebra- 
do, el sector público desmoralizado e ineficiente y las actividades productivas deprimidas y altamente subsidiadas"... $\mathrm{He}$ aqui algunos datos confirmatorios. El déficit fiscal podria superar los $\$ 1.400$ millones, sumado ello a un retraso en el pago del servicio de la deuda externa por valor de $\$ 160$ millones. Se estima que la mora pendiente de la banca nacionalizada rondaba los $\$ 2.600$ millones. Se recibe un INCAFE insolvente en sus compromisos de pagos $y$, en general, el remanente del erario público no dejaba mucha capacidad de maniobra para el segundo semestre gubernamental. El triunfalismo electoral se ensombrecía un tanto ante las obscuras perspectivas económicas. De todas formas habia una razonable disculpa y una comprensible aceptación. Se habia recibido una herencia difícil y se tenia bien claro to que habla que hacer.

La herencia dificil tenia, a juicio del nuevo gobierno, tres causas principales: la creciente y desmedida intervención estatal, las reformas económicas bajo edicto de nacionalización de sectores estratégicos y las ideologlas subversivas importadoras del conflicto armado civil. la historia de nuestra crisis arrancaria de 1980, y de acuerdo a la Secretarla Nacional de Comunicaciones son cuatro los grandes culpables: los terroristas, los políticos irresponsables, los funcionarios y particulares comptos, junto con el estancamiento de la economía y la cultura del fraude fiscal $^{2}$ Los daños materiales atribuidos a los terroristas alcanzarian los $\$ 4.000$ millones. EI PTB se contrae y estanca, y si lo distribuimos mentalmente entre todos los salvadorenos regresamos a niveles de 1960 . El pais está sin dólares, de acuerdo al informe, lo cual sumado a la mora irrecuperable del sistema bancario muestra el desfalco del proceso de su nacionalización. Las instituciones autónomas se reciben con deudas pendientes de $₫ 1.500$ millones, mientras que la deuda interna y externa del anterior gobierno se habia incrementado en $\$ 1.440$ millones y $\$ 1.880$ millones respectivamente. Por su parte la cornupción completó danos semejantes a los del terremoto de 1986.

La década de 1980 era un tramo de nuestra historia rasgada por los tirones de tres grupos contendientes, cada uno contra dos. El sector privado se sintió desposeido por el Estado y la guerrilla; el mismo Estado resultaba malquisto para el sector privado y para el grupo de los insurgentes, asi como estos últimos eran el enemigo capital de los dos anteriores. Quedaba el cuarto grupo, el pueblo, los más pobres de

1. FUSADES. Boletín Económico y Social. Ne 53; abril-1990; pág. 1.

2. Secretarla Nacional de Comunicaciones. Gobierno de la República. "Causas de la crisis que estamos superando". El Mundo. 17-abril-90; pp. 15. 
los pobres, que no se sentian a gusto ni con la guerra, ni con el Estado, ni con el sector privado. Era preciso reestructurar estas correlaciones de fuerzas; era preciso devolver al sector privado su función de liderazgo económico, limitando la ingerencia estatal a los términos no asequibles al primero. Se intercambian las funciones de protagonista principal y subsidiario. Respecto a la insurgencia y al conflicto armado, el inicial proyecto de mejorar la guerra para cambiar el curso de la guerra no estaba dando resultado; era necesario, aunque no agradable, anunciar el reinicio del diálogo. Las presiones externas y el escenario internacional de un mundo en diálogo aconsejaban la negociación oral.

Sobre la nueva correlación de fuerzas arrancaria el modelo de economia social de mercado como el enmarque donde se iria realizando el programa de estabilización y de ajuste estructural, expuestos en el Plan de Desarrollo Económico y Social, 1989-1994. Dejando de lado, por un momento, las ya iniciadas y no terminadas discusiones sobre la ideoneidad y viabilidad de un modelo de mercado que sea social en una sociedad marcada por las desigualdades, aflora el problema de que ya "el gobierno tuvo que enfrentarse a factores internos y externos, completamente ajenos a su control, que complicaron la ya difícil situación de corto plazo ${ }^{3}$.

\section{La hlstorla no comlenza en 1990}

De julio a julio los miembros del gobiemo y los proyectistas del modelo emergente nos han venido repitiendo, hasta el aburrimiento, que el principio del mal hay que buscarlo en los inmediatos predecesores. Este repetitivo ataque no sólo es aburrido e insolente, sino que a modo de boomerang se revierte contra las explicaciones teóricas que nos vienen haciendo los hoy gobernantes. Los hechos y sucesos que han marcado la corta historia de 1989-1990, distorsionando las proyecciones económicas del actual gobierno, son los mismos que dominaron la década de los 1980 y por lo tanto distorsionaron también los planes de aquellos gobiernos, aunque esta realidad se hayan silenciado en la propaganda electoral. En los reportes oficiales y en todos los informes ministeriales de 1990 se nos dice que tres elementos adversos, fuera de control, han obstaculizado los planes del actual gobierno: la ofensiva armada de noviembre, la reducción drástica del precio mundial del café y la disminución de la ayuda oconómica de la AID. No se puede negar el efecto contractivo de estos tres factores; pero el partido oficial tampoco puede negar que estos tres mismos elementos, fuera de control, estaban bien presentes a bo largo de toda

3. FUSADES, Ibidem. p. 3. 
la década de 1980. Al informar y explicar su primer año de gestión ARENA debe admitir que hizo un mal informe y una mala explicación de la gestión de los gobiernos anteriores.

"La ofensiva terrorista de noviembre que causó tres mil pérdidas en vidas humanas y aproximadamente $₫ 600$ millones de pérdidas en recursos materiales. Lo anterior no incluye costos relacionados con actividades militares, pérdidas de dias de trabajo, incrementos en primas de seguros, ni inversiones postpuestas". (3) Ciertamente esta ofensiva armada causó lamentablemente toda esta serie de danos humanos y materiales no justificables; pero también nos demostró a los habitantes de la capital y zonas urbanas lo absurdo y lo irracional de la guerra, porque si todos sufrimos mucho, sufrieron especialmente más los más pobres de los sectores marginados. $Y$ queda por hacer la historia de quiénes mataron y destruyeron más...

Se impone aqui hacer una reflexión. Si un mes de ofensiva armada ha dejado estas cicatrices humanas y materiales en la capital y zonas urbanas ¿por cuánto no habrá que multiplicar los danos económicos, humanos y sociales de los diez anos de guerra prolongada, aunque ella no se librara en las calles de la capital? ¿No han sido muchos los ciegos que no veian las terribles consecuencias de la guerra mientras esa guerra se hacia a una prudente distancia geográfica? Durante mucho tiempo hemos escuchado que la economia y la guerra eran dos cosas distintas, que se podía hacer la economia y al mismo tiempo seguir haciendo la guerra; que era exagerada la tesis de que viviamos una "economla de guerra", es decir que la guerra era el gran regulador de toda la economia en 1980, asi como el modelo económico anterior a 1980 fué el gran regulador de la actual guerra. Como la economia y la guerra eran dos cosas distintas habia que incrementar la guerra para salvar la economia. Ași se justificaba una ayuda externa para la guerra y otra ayuda externa para la economia, olvidando que la primera esterilizaba los esperados esfuerzos de la segunda. Pero lo único que creció fué la deuda externa.

Hablar de diálogo en $1980 \ldots$ era antipatriótico; quienes buscaban la solución intensiticando la guerra estaban de acuerdo en que el Estado administrara la guerra. Aqui surge la contradicción de las explicaciones históricas. La guerra, por esencia es destructiva y deficitaria sobre todo en un pals que no produce los insumos materiales de la guerra, y nocesariamente el Estado que la administrara tenia que ser deficitario, porque no es el Estado quien administra la guerra, sino que ha sido la guerra quien ha administrado a los Estados, como to vernos en las grandes superpotencias hoy las más endeudadas. Quienes estaban 
más a favor de la guerra son los que ahora han acusado más ferozmente al Estado de ser el mal administrador de la riqueza pública. Racionalmente son ellos los que tienen menos razón para hacerlo. Lo irónico no termina en la explicación sino en la acción: recientemente hemos escuchado a varios miembros del poder ejecutivo que, si los EE.UU. disminuyeran la ayuda militar a El Salvador, el gobierno se vería forzado a hacer transferencias de fondos a la partida de seguridad y defensa nacional sacándolo de otros gastos e inversiones sociales. Una amenaza de reducción de ayuda militar -que un referendum popular apoyaria - ha bastado para que el gobierno declare que debería sostener la guerra a costa de otros servicios sociales.

Aquí subyacen dos fallas fundamentales. El gobiemo no se pregunta seriamente la razón de ser de la posible disminución de tal ayuda militar de parte de tan generosos acreedores. En vez de aceptar la realidad del irrespeto a los derechos humanos, de la impunidad y discriminación en la administración de la justicia, pretende atribuir el posible recorte a una mala imagen artificialmente gestada en el exterior. Esto es negarse a admitir que la imagen es la sombra de la realidad. Pareceria que un conjunto de hechos publicitarios, sumados a la misma agenda del diálogo, vienen a confirmar que además de imagen hay realidad. En segundo lugar la experiencia del primer ano de gobierno debería convencer al partido oficial que la principal causa del déficit y de la deuda pública fueron los gastos requeridos para sostener una guerra prolongada por los unos y por los otros. En su interpretación histórica y en su propaganda electoral enfatizaron más las deficiencias técnicas de la mala administración pública que la razón de ser, es decir el objeto adverso y perverso de la misma guerra. Así de una premisa falseada se deduce una torcida conclusión: el Estado es, por esencia y presencia, un mal administrador. Este deficiente silogismo puede revertirse ahora contra el actual gobierno, quien hoy por hoy sigue controlando las principales riendas de la economia nacional, y de acuerdo a los últimos informes del presente mes de julio ellos dicen que lo están haciendo bien. Si lo hacen bien y no juegan un papel subsidiario caeria por tierra la teoría que aplican a otros gobiernos. También cae por tierra la otra teoría de que sea posible gestionar y hacer economía junto con guerra prolongada. Nuestro profesor es la vida y no sólo la teorla.

Un segundo obstáculo a la buena gerencia del actual gobiemo es la adversa coyuntura intemacional. "Reducción drástica en el precio mundial del café. Desde julio hasta diciembre el precio del café disminuyó en un $61 \%$, pasando de $\$ 129$ a $\$ 80$ por quintal, afectado por la suspensión del sistema de cuotas de la OIC. Esta reducción tuvo un 
efecto particularmente negativo debido al $50 \%$ de la disminución de la cosecha 88/89, ya que El Salvador no tuvo oportunidad de compensar con volumen exportado la caida en los precios del cafe" (3) Si valen las estadísticas de 1989, aunque se silencie la posterior alza del precio del café, para explicar las dificultades del actual gobierno, también tendrán el mismo valor las estadisticas de nuestras exportaciones-importaciones de 1979 hasta fin de la década 1980. Aparece así otro elemento, fuera de control, que fué el segundo gran regulador del proceso económico en los últimos diez anos.

Se ha convertido en teoria oficial que el proceso de nacionalizaciones es otra causa adicional de la crisis generalizada. Sin embargo los proyectistas del modelo oficial poco dicen sobre el momento coyuntural y poco dicen sobre el modo tradicional de funcionamiento de los sectores nacionalizados. En otras palabras, silencian los efectos adversos de una crisis mundial por estanflación.

Dentro de menores discrepancias nuestras estadisticas oficiales muestran que tanto las exportaciones como las importaciones de bienes y servicios-1988, valuadas a precios constantes de 1962, se redujeron a un $59-60 \%$ de su valor en 1979 . Si deseamos medir el poder adquisitivo de nuestras exportaciones, valoradas en dólares, observamos una drástica perdida del poder de intercambio: el valor de las exportaciones -1988 ( $\$ 601,1$ millones) representa un $53 \%$ de su poder adquisitivo en 1979 (\$1.132.2), mientras que el gasto en importaciones se contrae levemente en un $4 \%$, de $\$ 1.040,1$ millones1979 a $\$ 1.006,9$ millones en 1988 . Dos simples datos suficientes para mostrar que la estanflación internacional, factor incontrolable, se tradujo en contracción real junto con alza interna de los precios. Si el actual gobierno y sus proyectistas aducen el contratiempo de la calda del precio del café, no deberían olvidar que esa calda de los precios y de los volúmenes se dio también en la década de los ochenta. El precio de los cafés-lavados FOB descendió de $\$ 167,75$ (1979) a $\$ 109,16$ (1987) subiendo a $\$ 130,80$ en 1988; los precios del café sin lavar FOB sufren una contracción más drástica de $\$ 155,39$ (1979) a $\$ 68,00$ (1988) también sufren una sensible caída los volúmenes exportados: 184 millones en kilogramos en 1980 frente a unos 125 millones de kilogramos en 1988. Aún es mayor la contracción del valor y volumen del segundo rubro exportado, el abodón. Es patente el efecto de la coyuntura intemacional sobre nuestras exportaciones tradicionales, variable determinante del proceso económico interno, y variable determinada extemamente por la coyuntura y poderes internacionales. Si el gobiemo-ARENA clama y declama que la contracción de los precios del café -1989 ha ejercido un efecto contractivo sobre otras 
variable macroeconómicas, incluido el impacto sobre el tipo de cambio y disponibilidad de divisas, ¿por qué no aplica el mismo análisis y razonamiento a la pasada historia económica?- Por esta razón su publicidad, centrada en un superficial y aburrido ataque a anteriores administraciones resulta impertinente, irritable, además de contraproducentes, porque se hace dano a si mismo.

La crítica del gobierno no sé ha centrado tanto en la situación coyuntural del café sino en la creación del INCAFE. Hay que decir que este decreto de nacionalización tenia a su favor una seria justificación social. Como lo hemos comentado más ampliamente en anterior publicación $n^{4}$ el sector café no venia siendo un sector propiamente dinamizante de la economia interna, ni un sector propiamente social en la distribución de sus ingresos factoriales. Recurrimos para ello a la matriz insumo-producto-1978:

\section{Coeflclentes técnicos de la rama café (1978)}

- Consumo intermedio total (porcentaje de insumos)

- Sueldos, salarios y prestaciones sociales

0,0696636

- Consumo de capital fijo (amortizaciones) 0,2423010

- Impuestos indirectos netos de subsidios 0,0054669

- Excedentes de explotación 0,1791865

- C.B.P. de cada unidad en términos monetarios 0,5033820 1,0000000

Dado que una matriz nos describe una estructura de producción relativamente permanente podemos afirmar que la rama-café no era un sector dinamizante de la economia como demandante de insumos: el coeficiente de consumo intermedio es bajo $=7 \%$. Tampoco es dinamizante activo como suministrador de inputs por otros sectores. Su importancia radica en ser generador de ingresos internos y divisas externas. Sin embargo llama la atención que la suma de todos los sueldos, salarios y prestaciones sociales ronda escasamente el $25 \%$ del gasto total de producción (\$329.173 millones), mientras que el excedente de explotación retenia el $50 \%$ del valor bruto total ( $\$ 683.857$ millones), el doble del monto de todas las remuneraciones pagadas. El elevado beneficio del sector ofrecia un argumento bien positivo a favor de la socialización del sector estratégico, en cuanto exportador, del proceso económico. Veremos más adelante que una similar distribución factorial estaba caracterizando al conjunto de los 49 sectores privados productivos. La concentración económica, o estructura oligopólica, era

4. Ibisate Foo. J.: "A los cien dlas de gobierno: ¿hacia dónde vamos? ECA; agosto-septiembre-1989; p. $657 \ldots$ 
una caracteristica típica de nuestro sector productivo, por cierto muy protegido arancelaria y fiscalmente a costa de los ingresos-egresos del erario público. Hay que decir que por encima de los desatinos administrativos, el proceso de nacionalización se inicia a contracorriente de la estanflación mundial, que diezma el valor de nuestras exportaciones al mismo tiempo que encarece el costo de las importaciones. Seria más honesto decir que lo sucedido en 1989-1990 es un apéndice porcentual de lo iniciado desde 1980.

Al mismo tiempo, desde el sector monetario externo, nos afectó la coyuntura internacional. Las medidas antiinflacionarias aplicadas por la administración-Reagan (1980: teoria de la oferta) se traducen en una elevación del tipo de interés mundial junto con la revaluación del dólar. Si de esta fecha arranca la crisis de la impagable deuda externa del tercer mundo, es claro que nuestra economía se resentirá inmediatamente con el mayor precio de las importaciones, las crecientes tasas de interés en los nuevos préstamos, la aparición del mercado paralelo, la devaluación del colón en 1986 y la triplicación del servicio de la deuda externa. La adversa coyuntura internacional nos golpea por el doble flanco de las exportaciones e importaciones, por el sector real y monetario de nuestra economia; a la par que la guerra civil no debilita desde dentro. Estos fueron los dos grandes reguladores de nuestra economia en la década de los ochenta como lo siguen siendo en nuestros dias. Para ganar el apoyo y el esfuerzo de todos los grupos en el trabajo común ayudaria más decir toda la verdad que sólo una porción partidista de la misma.

En este contexto de deficits y deudas extemas se inicia la nacionalización del sector bancario, otro ejemplo típico de oligopolio concentrado. También aqui las médias verdaderas resultan contraproducentes. Es claro que la adversa coyuntura internacional, la creciente deuda externa, sumada a la especulación interna, debilitan el juego activo del sistema bancario. Es cierto también, desde tiempos muy pasados, que toda la estructuración de la autoridad monetaria, a partir de la composición de la Junta-Monetaria y del poder presidencial en el nombramiento de directivos mayores y menores del sistema bancario, posibilitaban una politización del créditos; aunque al sector privado típico nunca le ha faltado suficiente crédito y financiamiento, como to muestra el problema de la mora bancaria. Pudo haber y hubo su corrupción, incluido el tráfico ilegal de dólares, de acuerdo a recientes descubrimientos. Pero en el análisis de la banca nacionalizada y en su contrapunto a privatización aparecen datos curiosos, por no decir

5. Hem; pp. 658-662. 
irónicos. El actual Plan de Desarrollo proyecta algunas "políticas de captación de las remesas de emigrantes (p. 34) por ser la segunda fuente de ingresos extemos. Se quiere asi abastecer el ahorro, frenar la salida de capitales y propiciar el financiamiento de inversiones sociales afines a las necesidades familiares de los emigrantes. Entendemos que ésta será una de las funciones de las nuevas casas de cambio y del sistema bancario una vez privatizado. Pero si el actual gobierno quiere alentar la llegada de estos "pobre-dólares" para reforzar el ahorro y el crédito nacional, ¿por qué en su análisis de la banca nacionalizada silencia la fuga de unos $\$ 2.000$ millones (que no eran pobre-dólares) en los tres primeros años de la década de los ochenta? -Esa suma equivale al monto de nuestra deuda externa, y no terminó ahí la fuga de capitales. No sería muy deshonesto afirmar que quienes más han criticado la reducción del crédito al sector privado sean los que más dólares han estado sacando al exterior.

Los cuestionamientos pueden avanzar más lejos por falta de datos, debido a la confidencialidad bancaria. Se afirma que la mora total, desfalco de la banca nacionalizada, alcanza los $\$ 2.600$ millones, si bien carecemos de momento de la lista sorpresiva de tales morosos. Puesto que a lo largo de la década el crédito y el refinanciamiento fué mucho mayor a la grande que a la pequena empresa ${ }^{6}$, es lógico deducir que es mucho mayor la mora de la gran empresa (incluidas ahi algunas cooperativas del sector reformado) que la mora de la mediana-pequena empresa. ¿Por qué el desfalco de la mora bancaria se le carga a quien concedió el crédito y no a quien dejó de pagarlo? ¿Dónde está la verdad y quién se resiste a que afloren los nombres de los deudores, porque los nombres de los bancos ya los conocemos? -De la confidencialidad nace la suspicacia: ¿no existe el peligro de que el sistema bancario privatizado - pase a ser dirigido, directa o indirectamente, por sectores empresariales con mayor mora interna y mayor volumen de dólares en el exterior? Ante un proceso tan obscurecido y velado hay lugar a cualquier pregunta; el velo tupido con que se cerró el caso del Banco Hipotecario, como telón de escenario, deja suponer que los actores no son de tercera categoria.

Tampoco se han visto libres de aguda crítica las cooperativas del sector reformado, tanto por ser cooperativas como por ser reformadas. El gran argumento es la contabilidad y los números rojos de sus estados financieros, pero sin mirar su historia. Si, por las razones

6. Arévalo Damas A., et alii: "Análisis comparativo de la banca privada y banca nacionalizada en El Salvador: 1971-1988. Tesis de Grado-UCA. Agosto1990. 
explicitadas, grandes empresas del sector manufacturero asi como grandes agricultores del oriente y poniente se han visto comprometidos en problemas de mora, pese a los elevados montos de refinanciamiento (6) no deberia extranar que muchas de las recién creadas cooperativas se hallen en semejante situación. Quienes más han criticado este proceso de reforma menos han reflexionado sobre su historia. Estas cooperativas nacen con el pesado gravamen de la deuda agraria, tomando en cuenta que algunas fincas no se revaluaron sino en visperas de la reforma. Nacen en el contrapunto de la coyuntura internacional, que afectará a sus exportaciones tradicionales y a sus insumos importados. El proceso de guerra prolongada les afecta mucho más, directa o indirectamente, que al conjunto de la manufactura y comercio urbanos. Pero hay otra razón que los críticos de la reforma deberian reflexionar. Por Decreto se pueden crear cooperativas, pero por Decreto no se pueden crear los coopeativistas. Se trata si de una brusca transfomación y también de una seria pregunta: ¿por qué los nuevos cooperativistas no le atinan a la buena gestión de sus propiedades? ¿No estará la culpa en el pasado y no sólo en el presente? - No deja de ser llamativo que laboriosos campesinos, quienes de generación en generación venian trabajando en estas fincas, no estuvieran ya preparados para realizar una buena gestión. Esto significa que su tradicional trabajo los capacitaba sólo para trabajar, pero no para administrar. Desde este antecedente histórico es igualmente dificil hacer propietarios privados o propietarios colectivos. El tarareado fracaso del sistema cooperativo hay que explicarlo también en razón del anterior régimen de administración privada concentrada. La historia fluye desde atrás, aunque ciertas teorias prefieran olvidar la historia.

\section{La historla no comlenza en $1980 . .$.}

Si por un momento nos trasladamos a los anos que preceden la década de los ochenta es porque existe el fundado temor de que no sólo la renta per-cápita, sino el propio modelo económico nos haga retroceder a un entorno similar al de aquella época. Baste una breve referencia a la década de 1970 , repitiendo lo escrito en pasada ocasión. La década de los setenta no es la más feliz en referencias estadisticas porque coincide con el inicio del proceso de estanflación internacional. Pero se dieron un conjunto de condicionamientos, hoy anorados, que relegaron al olvido los problemas de la estabilización y del reajuste macroeconómico. En esta década la economia presentó una tasa de crecimiento real promedio del $5 \%$, superior a la tasa de crecimiento poblacional. La balanza de pagos presentó un relativo equilibrio externo, donde unas partidas compensaron los déficits anuales de 
las otras, sin que hubiera presión por la devaluación monetaria. La deuda externa, tanto la pública como la privada, creció, pero era una deuda tolerable y pagable con un reducido porcentaje de nuestras exportaciones. Tampoco el presupuesto estatal planteaba un gravoso déficit, aunque su estructura de ingresos y el destino global de los gastos no hayan sido propiamente muy sociales. Pero contablemente habia un equilibrio.

El regulador de la economía era la "economía de mercado" y de libre empresa, muy poco impresionada por las orientaciones sociales apuntadas en el Plan de Desarrollo Económico y Social, 1973-1977. Incluso los gobiernos de esas décadas fungieron como "Estados-Benefactores" del sector productivo, tanto por la amplia y costosa infraestructura que le proporcionaron como por la propicia legislación arancelaria y fiscal con la cuál lo protegió y financió. Así mismo, estaban privatizadas todas aquellas instituciones que hoy se vuelven a privatizar. En resumen, se dieron las condiciones 0 prerrequisitos internos y externos, que ahora se afirma son la precondición para el desarrollo económico o servicio de la "deuda-interna" a favor de las mayorias laborales.

Sin embago puestas todas estas condiciones fundamentales aparecen meridianamente los verdaderos problemas de nuestra economia: la elevada concentración económica del capital y de la renta en relativamente pocas manos, a la cual se va anadiendo la concentración geográfica urbana frente a la desolación rural. El derivado o el negativo de la economia de mercado ha sido la situación de pobreza generalizada que afectaba a los dos tercios de la población. Ni la economia de mercado ni las precondiciones de los equilibrios internos y extemos lograron poner límite a esos dos problemas: concentración vesus pobreza generalizada. Más aún, la libre empresa o sector productivo influyente se resistió tenazmente a los intentos de transformación social, taponando con ello cualquier salida legal o parlamentaria favorable a estos cambios sociales. El recurso a la fuerza bruta y el recurso al "explosivo" datan de aquella época. Por ello cabe la pregunta: ¿quién inició la guerra y por qué se inició?

Al terminar la década los resultados macroeconómicos de un modelo de libre mercado no lo cualifican como economia "social". De acuerdo a los datos recogidos por la Matriz Insumo-Producto-1978, la distribución de ingresos factoriales entre los componentes del Valor

7. Ibisate Foo. J.: "A los cien dias del gobierno de Cristiani: ¿hacia dónde vamos? ECA; agosto-sept., 1989; pp. 649... 
Agregado de los 49 sectores productivos (1" edición de la matriz) era la siguiente:

Dlstrlbuclón factorlal del Valor-Agregado: 49 sectores, 1978

\begin{tabular}{|c|c|c|}
\hline 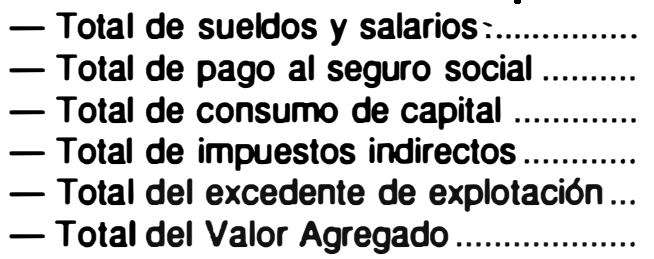 & $\begin{array}{l}\leftarrow 2.437 .228 \text { miles } \\
\leftarrow 110.018 \text { miles } \\
\leftarrow \quad 301.304 \text { miles } \\
\leftarrow 563.313 \text { miles } \\
\leftarrow 4.026 .214 \text { miles } \\
\leftarrow 7.526 .077 \text { miles }\end{array}$ & $\begin{array}{lr}= & 32.38 \% \\
= & 1.46 \% \\
= & 4.00 \% \\
= & 7.48 \% \\
= & 53.49 \% \\
= & 100.00 \%\end{array}$ \\
\hline
\end{tabular}

Las matrices intersectoriales ponen de relieve elementos estructurales relativamente estables, que manifiestan en este caso las relaciones y proporciones de distribución factorial. Tenemos que la amortización del capital superaba el monto de la seguridad social de la mano de obra. Los sueldos y salarios, que engloban las altas remuneraciones de gerentes y directivos, eran un $40 \%$ inferior al excedente de explotación, pese a que el número de trabajadores del primer grupo eran 54 veces más numerosos que el gnupo de empresarios. El volumen de sueldos-salarios pagados ese afo, incluyendo los del sector público, se aproximaba al $50 \%$ del valor del consumo privado de 1978 , mientras que sólo el excedente de explotación equivalia al $60 \%$ del mismo consumo privado. El problema de la concentración económica versus pobreza generalizada, analizado sectorialmente por otras investigaciones, quedaba confirmado globalmente en la distribución factorial del Valor Agregado-1978. ${ }^{\circ}$

Este paso atrás a esa década es para recordar que nuestra historia está hecha de sector privado y de sector público, de coyuntura intemacional y de estructura nacional y en cada etapa de esta historia resalta un común denominador: la presencia de los más pobres entre los pobres. ¿Por qué al hacer una explicación y una distribución de causa y culpabilidades seleccionamos ambigūamente los chivos expiatorios? -Si en la década de 1980 el Estado interviene más, en la década anterior-apenas interviene; si en la década de 1980 se hace presente la izquienda, en las décadas anteriores la derecha era la omnipresente; si en la década de 1980 se dice que hay más de planeación central, en las décadas anteriores todo estaba planificado por el mercado. En una y en otra coyuntura el común denominador es el mismo: la pobreza

8. Bisate Fco. J.: "Economla social de mercado y economla social con mercado". ECA. Abril-mayo, 1989; pp; 320... 
generalizada. A este problema fundamental es la que hay que buscarle la explicación, en singular y en plural, y a este mismo problema habria que adaptar el modelo económico. Al parecer nos resistimos a crear un modelo al servicio de la pobreza por razones varias; quienes elaboran los modelos económicos, y otros muchos, no vivenciamos personalmente la pobreza y en cada etapa le sehalamos un nuevo más allá como emanación de la teoría del rebalse. Hacemos teorias y modelos de la riqueza que no suelen servir para la pobreza. Un modelo para la pobreza nos sigue pareciendo no rentable ni para los de dentro ni para los de fuera, nuestros acreedores. No parece que esto sea cierto, y hemos intentado probarlo con un inicial modelo macro-econométrico*. En el fondo un modelo para resolver la pobreza sería un modelo de sobriedad nacionalizada, sin importaciones suntuarias, sin géneros de vida y de gastos de vida irritantes para las mayorias, sin tanto consumismo. Nos falta sinceridad económica y también a los que nos imponen los modelos.

Llegado aqul, hay suficiente base histórica para poner en entredicho los principios reguladores de la nueva economía de mercado. $Y$ ello por una razón: los modelos económicos no funcionan, ni en el Este ni en el Oeste, de acuerdo a sus principios teóricos, sino conformados a cómo los entienden y como los aplican quienes retienen el poder de dirigir y hacer funcionar cada modelo. Este es el dilema en nuestro país: una triangulación de poderes que puede derivar hacia un resultado poco social. Sin mencionar la adversa coyuntura internacional y la guerra, que esperamos termine en paz, el poder principal está en manos de nuestros acreedores intemacionales; ahi se gestó el modelo a nlvel continental. Nuestros amigos acreedores nos dicen: deben, luego deben pagar. Juridicamente hay que pagar el servicio de la deuda a los organismos financieros internacionales y privados, so pena de vemos recortados en créditos. Pero objetiva y éticamente hemos dejado de ser deudores; si se evaluase el verdadero flujo de capitales hacia el Norte resultamos acreedores. Los $\$ 4.000$ millones de ayuda de la AID ya han sido pagados con creces con todas las divisas (\$) no canceladas a nuestros emigrantes salvadorenos. Un somero cálculo de salarios-hora, meses trabajados y número de emigrantes en los EE.UU. mostrarla que la deuda se ha convertido en crédito. En estos cálculos trabajaban el Dr. Segundo Montes en la vispera de su asesinato. Esta ayuda real no se contabiliza, pero al menos sirve a quitamos a unos el complejo de deudores y a los otros el complejo de acreedores. Sin embargo

9. Orellana Alba M". Necosidades básicas y reáctivación de la Economla. Tesis de Grado. UCA. julio-1987. 
nuestros acreedores nos imponen un modelo que, por rebalse, podrá algun dla hacer algo por la satisfacción de las necesidades básicas.

En segundo lugar, en otra esquina del triángulo, el gobierno, no por ser Estado, sino por definirse como este subsidiario y por afiliarse al juego espontáneo del mercado. En tercer lugar el sector privado, término muy amplio, pero con el real peligro de quedar reducido a pocas manos. Liberalización y privatización en nuestra historia ha significado concentración. Este peligro antisocial no es ajeno a los principios filosóficos y postulados económicos del modelo de mercado.

\section{Los princlplos fllosoflcos de una socledad libre}

La parte introductoria del Plan de Desarrollo Económico y Social: 1989-1994 es una fiel transcripción de las bases doctrinarias de la estrategia de desarrollo económico y social y de los principios básicos de una economía de mercado", publicado por el Departamento de Estudios Económicos y Sociales de FUSADES ${ }^{10}$. No es ningún secreto, ni tiene por qué serlo, que FÜSADES es el inspirador directo del modelo oficial de mercado, institución que promueve varias publicaciones y conferencias en el pals; pudiera también convertirse en el fiscal si el gobierno se desviara de las vias marcadas. Hecha la consideración, la pregunta lógica es ¿quién inspira al inspirador?

Cinco son los principios filosóficos o bases doctrinarias, a los que se agregan cuatro postulados de la economia social de mercado, en la estructuración presentada por el Plan de Desarrollo. Una sociedad que quiere ser libre en el plan económico, político y en el orden de los vabres y costumbres tradicionales debe apoyarse en los siguientes principios:

A. El hombre es el fin de toda la sociedad.

B. La libertad es la base del progreso humano.

C. La igualdad ante la ley es la garantla de la paz social.

D. La justicia garantiza a cada quien lo que le corresponde.

E. El Estado desempena un papel subsidiario.

Estos principios filosóficos requieren un mecanismo de funcionamiento, una estructuración nacional que haga posible su actividad, es decir el logro de una sociedad más libres. Aquí encajan los cuatro postulados de una economía de mercado, que el Plan de Desarrollo califica normalmente como social. I ns Dostulados básicos son los siguientes:

10. FUSADES: Hacia una economia de mercado en El Salvador: bases para una nueva estrategia de desarrollo económico y social". Mayo, 1989. 
1. La propiedad privada es condición necesaria para la eficiencia de la producción.

2. El mercado libre asegura la mejor asignación de los recursos.

3. La competencia garantiza el funcionamiento del mèrcado.

4. El Estado tiene un papel subsidiario.

Al intentar ensamblar principios filosóficos y postulados económicos brota un torrente de preguntas, dudas y recelos teniendo presente nuestra historia. Es de suponer que aunque a estas bases doctrinas se les llama principios no quiere decir que ya existan al principio del modelo: todavia el hombre no es el fin de la sociedad, ni todos son libres, ni todos son iguales, ni el Estado es el subsidiario de los pobres. Según esto la tesis fundamental serla que estos principios se alcanzarlan al final gracias al juego de la propiedad privada, el libre mercado y la competencia interempresarial, quedando el Estado supeditado a completar to que no haga el mercado. Comencemos por algun lado, todavia a un nivel más bien teórico.

Lo que se busca es que toda la sociedad sea libre, pero leyendo los principios filosóficos desde los postulados económicos parece que el objetivo final es lograr que algunos hombres privados sean libres. No se percibe una estructuración civil de una sociedad libre, sino una simple sumatoria de individuos libres, donde la libertad se define como ausencia de coacción y no como responsabilidad social. De acuerdo a nuestra historia son minorla los que gozan de la propiedad privada; son minoria los que tienen las riendas del mercado y son mayoria los que obedecen a las fuerzas, llamadas leyes, de ese mercado. La competencia sin calificativo no garantiza nada. La competencia perfecta de que hablan los economistas, es tan perfecta que no es competencia; y quizás pueda hallarse en nuestra economia informal. Pero en nuestra oconomia formal to que tradicionalmente ha existido es la competencia imperfecta, la oligopóica-monopólica; y esta competencia es imperfecta porque no puede ser social tal como lo reconocen los principios de la economia social de mercado en el pals que dió nombre al modelo.

Uno de sus libros clásicos se expresa asf sobre la función del Estado en relación a la competencia empresarial. ¿Cuál es el papel del Estado a este respecto? - Tiene que proteger la compotencia contra su alteración y eliminación mediante carteles y procesos de concentración. Debe convertifla en un campeonato con reglas fijas, supervisado por el Estado; debe proteger a los débiles e impedir a los fuertes que empleen su poder unilateralmente. Estas exigencias básicas distinguen a los liberales antiguos de los neoliberales, o como a ellos mismos les gusta llamarse, los ordoliberales (del latin, ordo=orden). Pero las 
exigencias del nuevo orden van mucho más allá. Según la concepción liberal el Estado tiene hoy indiscutiblemente la función de estabilizar el valor monetario, crear condiciones favorables para un alto nivel de empleo, mantener la libertad de intercambio económico intemacional, y corregir la distribución de las rentas, con el objetivo de una mayor Justicia social"11

Desde los principios teórico-prácticos de este clásico párrafo podemos reflexionar sobre los postulados económicos que regirán nuestra economia de mercado. El primer postulado se centra en la propiedad privada como condición para la eficiencia de la producción. Si propiedad y eficiencia son los dos ejes de un mercado en competencia, es menester asegurar la propiedad y la eficiencia tanto del lado de la oferta como del lado de la demanda. Como lo subraya toda la ensenanza de la economía social de mercado existe ya un problema de propiedad discriminante del lado de la oferta: monopolios y oligopolios a combatir firmemente por el Estado. Siendo éste un problema estructural en nuestra economia, con todo no termina ahi el problema de la sana competencia. No puede haber un mercado en verdadera competencia si no se asegura la propiedad y la eficiencia de la demada, es decir del conjunto de demandantes. En caso contrario tendremos una tirania del productor sobre el consumidor y un mercado que no responde eficientemente a las grandes necesidades de la gran demanda. Si la competencia garantiza el funcionamiento del mercado, y el mercado es oferta y demanda, no se trata sólo de lograr la competencia entre los oferentes, sino entre la oferta y la demanda. Este es el problema más grave en nuestro país. No bastaria para ello la función de estabilización del valor monetario (inflación de oferta más que la inflación de demada en el pais), sino integrar la doble función "de crear condiciones favorables para un alto nivel de empleo (única propiedad de la mayoría de demandantes) y corregir la distribución de las rentas con el objetivo de una mayor justicia social". Al decir que "las exigencias del nuevo orden van más allá" cae por tierra nuestro cuarto postulado: el Estado tiene un papel subsidiario. Al sostener este principio queda bien al decubierto que los tres primeros postulados se centran y concentran en favorecer la oferta. Bajo nombre de economia de mercado se propone una economia planificada por una parte del mercado. Caemos en el mismo problema criticado acremente a los socialismos reales del Este europeo: una tirania del productor sobre el consumidor a través ahora del mecanismo del mercado.

De hecho lo que se pretende realizar es un difícil matrimonio de

11. Fack Fritz: "Economia Social de mercado: una introducción". Frankfurt. 
modelo liberal-FMI-AID con ciertos aspectos de economia social de mercado; este matrimonio está condenado al divorcio. Se contradicen unas y otras políticas. La política cambiaria, siendo justa y necesaria como mecanismo de ajuste de nuestra balanza de pagos, viene a fortalecer de nuevo la concentración de ingresos y de poder en un sector agroexportador; indirectamente, supuesto un proceso de liberalización de las importaciones, se renovarán los gastos en importaciones suntuarias, menos necesarias, en vez de preferenciar las importaciones requeridas por los sectores más dinamizantes de la economia, que son los que responden a la satisfacción de las necesidades básicas (9).

Las políticas de privatización, junto con la creación de las casas de cambio, presentan el histórico peligro de una nueva concentración en la captación del ahorro y en la distribución del crédito. Se ha blandido inoportunamente el peligro de la politización de la banca nacionalizada para recaer en el peligro de politización de la banca concentrada. Tampoco se puede confundir la necesidad técnica de la fusión bancaria con el riesgo de la concentración de la gestión bancaria, aunque se distribuyan los títulos-acciones entre múltiples empleados o ferceras personas; siempre queda el mismo riesgo de politización en el nombramiento de los directivos del sistema bancario, que siguen viniendo de arriba. Como lo analiza la investigación apoyada por CENITEC y realizada por una misión alemana, más allá de la multidistribución de acciones (p. 46) están los problemas de eticidad, honestidad y tocnicismo a nivel de cada institución y del conjunto del sistema bancario $^{12}$. Aparte de los interrogantes que levanta el proceso de banca en mora o banca privada, está el interrogante de esta liberalización sumada a las otras liberalizaciones, o trilogia del exportador, productor, banquero.

También se da un fuego cruzado entre las hipótesis del programa de ajuste estructural y los requisitos de una economia social de mercado. El programa de estabilización y de ajuste estructural se basa en la hipótesis de que nuestra inflación es una inflación por demanda, centrada en la demanda del sector público y en ciertas presiones de la demanda privada a controlar con salarios normados por la productividad. Resulta empero que nuestra inflación no deriva eminentemente de un empuje de la demanda sino más bien de los costos de producción. El Estado no ha gastado mucho sino más bien poco para responder a sus funciones clásicas, sobre todo su gasto e Inversión

12. CENITEC: DIES: "EI sistema financiero de EI Salvador. Anállale y porepectivas. Cuadernos de Investigación; 2; mayo, 1989. 
social. El Estado entró en déficit cuando tuvo que financiar una función que ni es clásica ni es social: la guerra. Pero se saca el argumento a nivel de principio y a nivel de postulado económico: el papel del Estado os subsidiario, cuando más se impone el gasto y la inversión social. Esta función del Estado, en cuanto generadora de empleos, no deberla relegarse a la parte quinta del Plan de Desarrollo ("Politicas de sustentación del plan de desarrollo económico y social"), si queremos una economla social y un Estado dedicado a "corregir la distribución de la renta con el objetivo de una mayor justicia social".

Esto es tanto más necesario por dos razones. Por un lado nuestra Inflación, que es ante todo una inflación de costos, tiende a desbordarse apoyada por una política de liberalización de los precios. Los precios suben no por presión de la demanda sino por acumulación de costos de producción, como se reconoce en los esfuerzos por lograr una reconversión industrial (p. 34-Plan). Un sector productivo, que en décadas pasadas fué protegido en calidad de industria naciente con elevados aranceles y sensibles exenciones fiscales, welve ahora a ser protegido con la política de liberalización de precios. Sumando y restando, ël conjunto de las nuevas políticas comerciales y fiscales buscan catalizar y volver a proteger al sector del capital. Por el otro lado, ya que no podemos competir por costos de capital, se buscan las ventajas comparativas en la mano de obra, fijando salarios de acuerdo a su productividad. No es tarea fácil desmembrar técnicamente la productividad factorial de los componentes de una columna de matriz intersectorial; dificultad que nace del cálculo de la productividad física como sobre todo de la productividad monetaria cuando tenemos precios oligopólicos frente a precios deprimidos. De todas formas, bajo el recurso de la productividad se pretende legitimar que sean las fuerzas del mercado quienes diriman la remuneración; el único proteccionismo serán los decretos de salarios mínimos, sin que existan decretos de salarios máximos. Realmente las políticas de estabilización y ajuste estructural difícilmente encajan en el marco inspirador de una economia social de mercado a la alemana, donde los principios de la socialdemocracia y el hecho de que son alemanes disciplinados le han dado su cariz de más social. No es de extranar que los éxitos relativos de los programas de ajuste estructural se hayan logrado bajo regimenes seudodemocráticos 0 a costa del factor trabajo. No significa esto que no haya en el presente Plan de Desarrollo un conjunto de aspectos positivos que buscan elevar la capacidad y calidad productiva, la diversificación de la producción, la eficiencia de la administración pública y luchar contra la corrupción o la impunidad en cualquier categorla social. Pese a las buenas intenciones lo que se puede prever es que la 
conjunción de los principios filosóficos y postulado económicos, por parte de quienes los van a aplicar, no nos conduzcan a la construcción de una sociedad democrática.

\section{La democracla en los principlos y postulados del modelo}

Leidos y meditados los principios y postulados del modelo económico (Introducción del Plan de Desarrollo) se percibe una inspiración individualista, en el sentido de egocentrista, del hombre en sociedad. / La sociedad es vista desde el indiviuo y para el individuo, silenciando el movimiento complementario del individuo para la sociedad/No basta decir que "el hombre es el fin de toda sociedad", sino se anade que "la sociedad es el fin del hombre". Al subrayar el individualismo se silencia el carácter de la solidaridad humana. Es llamativo que al sehalar los derechos del ser humano no se haga el mismo énfasis en los deberes sociales. Incluso la referencia o el argumento religioso en que se quieren fundamentar los derechos humanos es unilateral e imperfecto. "Los derechos del ser humano emanan de la naturaleza misma y tienen su origen en el Creador". Si se invoca al Creador conviene hacerlo con los dos pulmones y no sólo con uno, porque el Creador también nos ha impuesto deberes sociales: no matarás, no robarás, no mentirás, no calumniarás, no codiciarás los bienes de tu prójimo, no hagas a los demás to que no quieras que te hagan a ti, y como broche de oro, ama a tu prójimo como a ti mismo. La solidaridad y la justicia social no quedan muy iluminadas en estos principios filosóficos.

Se presenta la libertad como "la base del progreso humano". Una vez más se trata de un enfoque eminentemente egocentrista. FUSADES y el Plan de Desarrollo dicen que "por libertad entendemos simplemente la ausencia de coacción en todos nuestros actos". FUSADES y el Plan afirman algo muy importante, pero to afirman simplemente, en sentido individual. La coacción es lo que estructuralmente viene tipificando la existencia de gran parte de los habitantes en nuestra sociedad y en el continente. Sin pensarlo ni pretenderlo están haciendo referencia a la inveterada coacción social cuya eliminación es el objetivo de la teologia de la liberación. Libertad y liberación suenan parecido, pero significan en este caso lo contrario. Se afirma un aspecto y se persigue al segundo; esto es individualismo. La definición de libertad se hace simplemente también en otro sentido. La libertad supone ante todo responsabilidad: ser responsable de mis actos. La responsabilidad integra tanto los derechos como los deberes. Dijimos que en esta cualidad se basa todo el derecho, que integra los derechos junto con los deberes, y normalmente castiga las faltas a nuestros deberes sociales. 
Esta visión egocéntrica de la libertad, referida esencialmente a la libertad de mercado, desemboca en una sociedad atomizada. "El límite a la libertad de una persona radica en el punto en donde comienza la libertad de otra persona". Esta imagen de la sociedad a modo de mosaico de minifundios individualistas, de propiedad privada de mis actos, obscurece el aspecto de responsabilidad e interferencia de los actos humanos que son sociales porque son individuales. La libertad no nos ha sido dada para aislar y dividir sino para fusionar e integrar esfuerzos humanos.

Quedan dos principios filosóficos donde, 0 involuntariamente los leemos mal, o voluntariamente el Plan de Desarrollo quiere decir otra cosa. El primero de estos principios reza: "la igualdad ante la ley garantiza a todo ciudadano que, independientemente de su sexo, color, posición social, profesión, religión o afiliación política, el Estado le va a tratar de la misma manera. Eso implica que no hay favoritismos ni privilegios para nadie" / Aqui hay algo muy contradictorio con todo el modelo. El problema de nuestro país no está fundamentalmente en que el Estado no trate a todos de la misma manera, sino en que la propia sociedad civil no está estructurada para que todos sean tratados de la misma manera. Lo que especifica a nuestra sociedad es precisamente las desigualdades que nacen del sexo, del color, de la posición social, de la profesión, de la religión y de la afiliación política. Pedirle a la ley y al Estado que trate equitativamente a quienes la sociedad discrimina diferencialmente es pedir que la ley y el Estado procedan a toda una reestructuración de la sociedad, donde todos puedan ser más iguales. Para reestructurar la ley hay que reestructurar la sociedad, porque el derecho suele ser, en su aplicación, una emanación de la sociedad. Lo realmente positivo de este párrafo, y lo que si duda quiso decir voluntariamente el Plan, es el reconocimiento explicito de que la aplicación de la ley no ha sido hasta el presente equitativa. La administración de la justicia es ahora precisamente uno de los puntos candentes del clamor popular y del diálogo gubernamental. Con ello el Estado dejaría de tener un papel subsidiario.

Lo sorpresivo del anterior párrafo sube de tono cuando se nos explica como la sociedad va a administrar la justicia. "La justicia va a garantizar a cada quien to que le corresponde. Las doctrinas colectivistas, en nombre de la justicia social, legalizan el despojo y la arbitrariedad. Bajo una sociedad libre se concibe la justicia como el dar a cada quien lo que le corresponde... Bajo este concepto es el mercado el que determina cuál debe ser la retribución de los factores de producción y no el Estado. De aqui que cada quien obtenga lo que le corresponde". Para comenzar, deberiamos ser más honestos y obje- 
tivos para descubrir en nuestro modelo los vicios y errores que atribuimos a las "doctrinas colectivistas". No negamos ni silenciamos los errores sociales derivados de la concentración del pleno poder político y económico en una minoría privilegiada, y con la mayor honestidad y objetividad lo hemos descrito en dos de los últimos artículos $^{13}$. Si vemos la mota de polvo en el ojo ajeno, ¿por qué no vernos la viga en el propio ojo? -Precisamente en nuestra sociedad desigual ha sido la economia de mercado quien "legalizó el despojo y la arbitrariedad". La justicia conmutativa del mercado se basa en la propiedad privada, en el intercambio de propiedades. Lo estructuralmente malo de nuestra sociedad es que arranca de la desigual propiedad.

Pero hay algo más allá de la desigual distribución de to que entendemos por propiedad privada. Muchos hombres y mujeres ni siquiera logran obtener la propiedad de su propia persona al interior de su vida social. Cuando un gran número de ciudadanos ni siquiera poseen sus documentos de identidad, cuando un cincuenta por clento de la población se ve sometida al vacio del analfabetismo y de la mínima formación profesional, cuando a la suma pobreza se une la suma inseguridad de su derecho a la vida y al respecto de su dignidad, cuando el veinticinco por ciento de la población se ve desplazada de su lugar de origen, cuando caminan largas distancias buscando los servicios de salud, educación... porque estos servicios no caminan hacia ellos, cuando dos tercios de la población se ve sometida a la Incertidumbre del empleo, cuando el propio discurso oficial reconoce la existencia de los más pobres entre los pobres...; ¿dónde está la base humana y económica para sostener una justicia garantizada por la simple economla de mercado?

Realmente nos resulta dificil ponernos en línea con los principios filosóficos y los postulados económicos del presente Plan de Desarrollo. Ensamblando los cuatro principios tendriamos una sociedad al servicio de unos individuos, pero no unos individuos constructores de una nueva sociedad. Lo controversial y lo contradictorio vuelve a fluir en el enunciado del quinto principio, que es también cuarto postulado. El Estado tiene una esfera de acción bastante limitada en una sociedad libre, ya que su principal papel es el de velar porque se respeten las libertades y los derechos de las personas, y contribuir en forma eficiente a proveer a la población más necesitada de los servicios básicos

13. Ibisate Fco. J.: "La postperestroika en el bloque socialista...". ECA. Abrilmayo, 1990; pp. 291-314. Idem: "¿Hacia dónde va el Este, hacia dónde va el Oeste? Realidad económica y social. Enero-febrero, 1990. 
que no se pueden proveer a si mismos. Las funciones del Estado son dar seguridad a los ciudadanos, garantizar una administración de justicia neutral en la que no haya privilegios para nadie $y$ actuar solidariamente en la atención de los más necesitados de la población". Al acabar de leer este párrafo nos da la impresión de que la sociedad se divide en dos: el Estado de los pobres y el mercado de los otros.

Si todas estas son las funciones del Estado parece que no encaja bien el título de este principio: "el Estado desempena un papel subsidiario"; o en otras palabras", el Estado tiene una esfera de acción bastante limitada en una sociedad libre"... Aqui hay algo que no concuerda: o el título está mal puesto o el contenido del párrafo se refiere a otro pals. No se puede dar por supuesto que nuestra sociedad sea libre o que espontáneamente tienda a ser libre, cuando respiramos una atmósfera de miedo y violencia, dramáticamente traducida en nuestro via-crucis de muerte. No se puede presumir que se respetan las libertades y los derechos de las personas en el momento mismo en que se clama y reclama por la equitativa administración de la justicia, en que otros paises nos recortan su ayuda mientras no se den pruebas objetivas del respeto a los derechos humanos, en el mismo momento en que los temas de impunidad, desmilitarización ...pertenecen a la agenda nacional. Si los autores del Plan de Desarrollo adjudican de veras todo este conjunto de funciones civiles y de actividades económicas al Estado no entendernos quién les inspira para que se minusvalúen a si mismos y minusvalúen al Estado que representan. De hecho la extensión del Plan de Desarrollo, la multiplicidad de áreas y políticas programadas, su calendarización en el tiempo y su aplicación geográfica en un pais que demanda toda una reestructuración en el espacio físico y una apertura hacia el istmo centroamericano, es suficiente razón para defender la función motriz de la Administración Pública. Para poner coto al aspecto de politización, en el sentido de partidismo del Estado, el actual gobiemo y los que le sigan deberian generar conciencia de esos dos conceptos: Administración y Pública.

El Estado, en cuanto administración, debiera exigirse el mayor tecnicismo en sus miembros directivos y ejecutivos, ascendiendo a estos puestos por concurso de capacidad demostrada y no por el compadrazgo de partido. Esta mala práctica, repetida con cada gobierno, resta estabilidad y capacidad técnica a la administración pública. Esto lo resienten los graduados universitarios con títulos básicos o de postgrado, que miran esos puestos como interinos y deslizantes. Pierde con ello el Estado el carácter de estabilidad que el calificativo de "pública" anade al aspecto administrativo. Los problemas del Estado vienen de lejos y requieren del mediano y largo plazo para irles dando solución. 
Si se programa una reconversión industrial y una actualización técnica del sector privado, el mismo énfasis se requiere en el sector público para que se vaya desterrando la imagen de partidismo, de ineficiente e incluso de posible corrupción.

La función del Estado no puede calificarse de subsidiaria, de supeditada a lo que otros no hagan. No es cuestión de superticie o de extensión que ocupe el sector privado y el sector público; es cuestión de funciones propias de economias en desarrollo, funciones que se complementan y se necesitan mútuamente. En una explicación, bien imperfecta, pudiéramos decir que en el socialismo real el mercado vendria a ser la voz de los sin voz y que esta misma seria la función del plan en una economia capitalista en desarrollo. Pero esta imagen es imperfecta porque nos daria a entender que plan y mercado son dos poderes compensadores enfrentados. En realidad lo que debemos buscar es que plan y mercado sean dos fuerzas motrices y complementarias. En su fase de post-perestroika, las economias del Este europeo comienzan a hablar del "mercado orientado por el plan". Dejando de lado posibles susceptibilidades, ésta pudiera ser nuestra línea de acción: que el plan oriente al mercado. Nuestro temor es que sea el mercado quien oriente y domine al plan.

Este temor se fundamenta en la misma estructuración de nuestro Plan de Desarrollo Económico y Social, dividido en dos partes. Arrancando de los principios filosóficos de una sociedad libre, la primera parte se titula "Plan de Desarrollo Económico", sustentado en los postulados económicos mencionados, y se concentra en las políticas de estabilización y ajuste estructural del corto-mediano plazo. Fundamentalmente éste serla el imperio del mercado, de la competencia empresarial, apoyada por una política global y sectorial de inversiones públicas. La segunda parte, quizás parte subsidiaria, integra el "Plan de Desarrollo Social", subimperio delegado fundamentalmente al Estado. Pero este subimperio social abarca el gran mercado económico de la educación, la salud, la nutrición, la vivienda, la familia, la previsión social, el empleo y el deterioro ecológico. Los breves diagnósticos (pp. 64...) que introducen cada uno de estos acápites son suficientes para ponderar todo to que hay que cambiar y mejorar.

Aunque el plan invite a una "participación privada... y no ser una responsabilidad exclusiva del Estado" (p. 57) de hecho se cieme un doble peligro. En virtud de los principios filosóficos y de los postulados oconómicos el mercado espontáneamente se concentrará en la primera parte, que se ha dado en llamar "desarrollo económico" y no tanto en el titulado desarrollo social. En segundo lugar, tampoco el Estado go- 
zará de amplia maniobra de acción sobre el desarrollo social si se le restringe su gasto corriente y de inversión, si por principio debe reducir su demanda y si, por conclusión, el Estado es un mal administrador de la cosa-pública (res-publica). Tanto el plan como el presente comentario nos deja entrever el cúmulo de deficiencias civiles sumadas a las grandes necesidades económicas no atendidas por la sociedad: una sociedad compuesta de sector privado y de sector público. La herencia recibida es difícil: ¿quién va a orientar a quién para cambiar y para mejorar? La pasada historia de nuestra economia de mercado nos hace tener que volvamos a una historia pasada. 